\title{
O brincar como experiência criativa na psicanálise com crianças ${ }^{\star}$
}

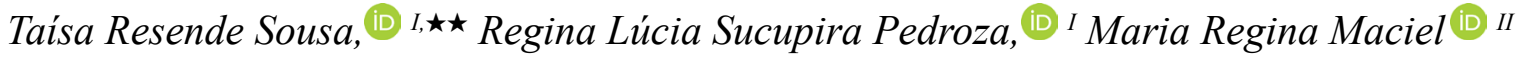 \\ ${ }^{I}$ Universidade de Brasília, Brasília, DF, Brasil

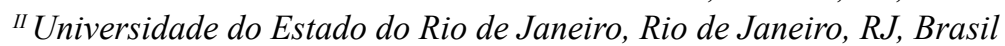

\begin{abstract}
Resumo
O tema investigado é o brincar como experiência criativa na psicanálise com crianças, partindo das contribuições freudianas e aprofundando os conceitos winnicottianos, sobretudo em relação ao brincar: uma noção que vai além do modo de expressão característico das crianças, relacionado à continuidade do ser. O objetivo é refletir essa temática, considerando o brincar como fenômeno transicional e experiência criativa própria à expansão do self. Duas vinhetas clínicas são trazidas, a fim de ilustrar as construções teóricas da psicanálise com crianças, do brincar, do jogo do rabisco e da melodia como fenômeno transicional. A título de conclusão, recorremos a uma série televisiva canadense, Anne with an " $E$ ", para refletir sobre a vida de uma adolescente que foi adotada por uma família que conseguiu ser um ambiente suficientemente bom. Assim como nas sessões analíticas, entendemos que é preciso haver uma disponibilidade para brincar, bem como um encontro frutífero entre as pessoas para que elas possam concretizar seu potencial criativo.
\end{abstract}

Palavras-chave: brincar; experiência criativa; fenômeno transicional; psicanálise com crianças.

\section{Play as a creative experience in psychoanalysis with children}

\begin{abstract}
This study focuses on the play as a creative experience in psychoanalysis with children, from Freudian contributions and deepening in Winnicott's concepts, especially in relation to playing: an assumption that goes beyond the typical way children usually express themselves, regarding the continuity of the self. The objective is to reflect upon this theme, considering playing as a transitional phenomenon and creative experience peculiar to the expansion of the self. Two clinical vignettes are introduced, to illustrate the theoretical constructions of psychoanalysis with children, of playing, of the scribble game and of the melody as a transitional phenomenon. In conclusion, we used a Canadian television series, Anne with an "E", as a reference and inspiration to reflect upon the life of a teenager who was adopted by a family that managed to provide the young girl a suitable environment. Just as in the analytical sessions, we understand that there must be a willingness to play, as well as a fruitful meeting between people so that they can achieve their creative potential.
\end{abstract}

Keywords: play; creative experience; transitional phenomena; psychoanalysis with children.

\section{Introdução}

Para pensar a psicanálise com crianças, articulando-a com o brincar, consideramos necessário iniciar com as contribuições do pensamento freudiano. Em Escritores criativos e devaneios (FREUD, 1907/1996a), o autor discorre sobre alguns aspectos da vida infantil, introduzindo a ideia de que o brincar na infância corresponde à fantasia e à escrita criativa na vida adulta. Ambos os fenômenos (fantasia e escrita criativa) criam um mundo próprio ou, ainda, possibilitam que o sujeito adapte alguns elementos de seu mundo, tornando-os mais agradáveis. $\mathrm{O}$ autor afirma que tanto o escritor criando quanto a criança brincando criam um mundo de fantasia e o vivenciam com bastante seriedade. Vemos, portanto, que há algo que perpassa o adulto e a criança: o brincar criativo, que é comum ao brincar na infância e à escrita na vida adulta.

Se o brincar criativo perpassa adulto e criança, perguntamos: como fica essa experiência na clínica psicanalítica? Há alguma diferença entre o brincar de crianças e o de adultos na análise?

\footnotetext{
^ Fonte de financiamento: $\mathrm{CNPq}$

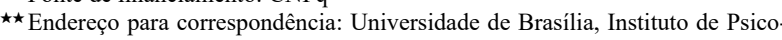
logia. Campus Universitário Darcy Ribeiro, Asa Norte, Brasília - DF. CEP 70910-900.E-mails: taisarsousa@gmail.com,rpedroza@unb.br, mreginamaciel@terra.com.br

Os dados completos dos autores encontram-se ao final do artigo.
}

Ao retomar o início da psicanálise com crianças, percebemos que Freud (1909/1996b) foi desenvolvendo seus estudos a partir de sua experiência com adultos, reconhecendo a sexualidade desde a mais tenra infância. Apesar de não ter atendido nenhuma criança diretamente, deixou algumas contribuições principalmente no texto "Análise de uma fobia em um menino de cinco anos". Com alguns encontros com o pai do pequeno Hans, fornecendo-lhe orientações, o autor pôde pensar algumas especificidades sobre a psicanálise com crianças (FREUD, 1909/1996b).

Para Freud, quando se analisa um adulto procura-se descobrir suas formações psíquicas, construindo hipóteses sobre a sexualidade infantil. O que o autor defende é a possibilidade de observar, diretamente nas crianças, alguns impulsos e/ou desejos sexuais que tentamos acessar por meio da fala do adulto. Nesse sentido, a psicanálise é uma medida terapêutica em que o analista oferece ao analisando uma interpretação possível de seus sintomas, para que o próprio analisando possa reconhecer e compreender seu material inconsciente. A análise trabalha a fim de que o paciente seja capaz de ter uma compreensão consciente de seus desejos inconscientes e consiga criar um sentido próprio para eles, o que acontece pela ajuda do método interpretativo. Quando Freud (1909/1996b) esclareceu a fobia de Hans em relação aos cavalos, pôde trabalhar a resistência que poderia impedir que os pensa- 
mentos inconscientes se tornassem conscientes, e o próprio Hans teve coragem de descrever os detalhes desta fobia, sendo parte ativa na condução da análise.

Em outro texto, A história de uma neurose infantil, Freud (1918/1996e) também discorreu sobre elementos da psicanálise com criança a partir das recordações e dos sonhos que o paciente adulto trazia no consultório, sobre a história de sua infância. O sintoma veio aos dezoito anos, mas Freud percebeu que os acontecimentos dos primeiros anos de vida eram fundamentais para entender o quadro clínico. Logo após o aniversário de quatro anos, o paciente havia sido dominado por um distúrbio neurótico: uma histeria de angústia, na forma de fobia animal (também como no "Pequeno Hans"), só que, desta vez, de lobos, que se transformara em uma neurose obsessiva de cunho religioso.

Nesse caso clínico, o pai da psicanálise utilizou-se, junto com o paciente, do recurso do desenho, para interpretar seu sonho com os lobos. Além disso, o analisando trazia várias recordações de cenas vividas na infância, o que, para Freud (1918/1996e, p. 61), não significa que essas lembranças anteriormente inconscientes seriam sempre verdadeiras: "Elas podem ser verdadeiras; muitas vezes, porém, são distorções da verdade, intercaladas de elementos imaginários, tal como as assim chamadas lembranças encobridoras, que são preservadas espontaneamente".

O sonhar poderia ser, então, outra maneira de lembrar e, ao mesmo tempo, de criar e imaginar. Pois uma recorrência nos sonhos pode ser a "explicação do fato de que os próprios pacientes adquirem gradativamente uma convicção profunda da realidade dessas cenas primárias, uma convicção que não é, em nenhum aspecto, inferior à que se fundamenta na recordação" (FREUD, 1918/1996e, p. 62). Tanto a criança como o adulto só conseguem criar fantasias a partir do material a que teve acesso, podendo ser pela leitura, pelas cenas do cotidiano ou por outra fonte.

A respeito do brincar, no texto Além do Princípio do Prazer (1920/1996f), ao observar seu neto de um ano e meio de idade que brincava naquele momento, Freud se indaga: por que as crianças brincam? E é a partir da observação detalhada desta brincadeira infantil que ele reconhece e interpreta o jogo do fort-da. Neste, o menino atirava um carretel para longe (quando emitia um longo e arrastado "o-o-o-o", acompanhado por expressão de interesse e satisfação). A mãe do menino e Freud (avô da criança) concordavam em achar que isto representava a palavra alemã fort (em inglês: gone, em português, traduzido como: ir embora). Puxava então o carretel e saudava o seu reaparecimento com um alegre $d a$ (ali). Então, esta era a brincadeira completa: desaparecimento e retorno. A interpretação deste jogo relacionava-se ao fato de deixar a mãe ir embora sem protestar, encenando o próprio desaparecimento e retorno. A experiência da criança se transformara em brincadeira, por repetidas vezes, passando de uma posição passiva para uma ativa, como forma de lidar com as pulsões, tanto de vida como de morte. O brincar caracterizava-se, assim, como um modo de a criança se expressar e elaborar a ausência materna.
A partir das contribuições freudianas, é possível evidenciar que a psicanálise com crianças possui algumas especificidades que a diferencia do trabalho com os adultos. Desde a criação da psicanálise, vemos como algumas mudanças em relação à técnica e ao método são importantes para a expansão psicanalítica, o que exige uma fundamentação teórica para sustentá-la. A cada atendimento, há um manejo necessário e uma reflexão sobre ele. Há um importante movimento: a teoria guiando a clínica e a clínica fundando, fundamentando e recriando a teoria. Mesmo sabendo da importância do método clínico psicanalítico em operar com o inconsciente, emerge uma necessidade de reconhecer as especificidades do trabalho com crianças, adolescentes, adultos e idosos. Na perspectiva winnicottiana, o manejo técnico é associado, sobretudo, ao brincar (FRANÇA; PASSOS, 2019). Dessa forma, é possível entender como Winnicott transformou a noção de análise quando fez uma aproximação com a noção do brincar, propondo uma ampliação de recursos utilizados pelo analista (FRANCO, 2003).

Podemos, assim, pensar o brincar não apenas como meio de expressão, mas também como experiência criativa. Winnicott (1975) faz da suposta barreira à associação livre da análise com criança, uma torção que modifica o que entendíamos, até então, sobre o brincar. Durante o processo analítico, as falas e as brincadeiras vão ganhando sentido, a partir do encontro entre paciente e terapeuta. Nesse caso, a dimensão do brincar vai se expandindo para além de modo de expressão característico das crianças, estando relacionado à continuidade do ser. Pela capacidade de experimentar e de vivenciar - com o outro - num espaço potencial (que não é fora e nem é dentro), o brincar como um fenômeno transicional pode acontecer.

$O$ conceito de transicionalidade ancora-se no encontro "entre" o mundo psíquico e o mundo socialmente construído. É um campo intermediário que se constitui tanto pela realidade interna quanto pela externa, o que é fundamental para entender o brincar na teoria de Winnicott. Existe também uma relação com o sentido da experimentação, tendo como pano de fundo as vivências de ilusão e de desilusão. As experiências de ilusão precisam acontecer antes da transicionalidade; e a desilusão advém de forma mais presente junto e após a transicionalidade (SOUSA, 2019).

No momento de vivenciar a ilusão, há uma mãe suficientemente boa, em sua preocupação materna primária, que se adapta de maneira quase completa ao seu bebê. Processualmente, essa adaptação vai se transformando em momentos pequenos de menor adaptação, quando o bebê vai demonstrando uma crescente capacidade de suportar essa ausência materna. Assim, bebês e crianças vão tendo um contato criativo com o mundo, apropriando-se da realidade externa e enriquecendo-se com suas experiências internas (WINNICOTT, 1975).

Com essas vivências, o indivíduo vai se constituindo, adquirindo o estágio do "eu sou", processo resultante da integração do ego. Com esse estado de diferenciação entre "eu" e "não eu", o sujeito caminha para uma conquista básica para o seu amadurecimento emocional e para a sua saúde: a construção de seu verdadeiro self e de 
seu sentimento de realidade. O analista, tanto de crianças como de adultos, pode auxiliar nesse processo de amadurecimento e de conquista do self (WINNICOTT, 1975).

O que Winnicott propõe é a construção de uma sessão viva e criativa, que busque a espontaneidade e a integração do self. É pela capacidade do brincar criativo do analista e do analisando que a sessão acontece, tanto com crianças quanto com adultos. Quando o paciente não é capaz de um brincar espontâneo, o terapeuta precisa auxiliar no desenvolvimento ou na recuperação de sua capacidade brincante, para posteriormente manifestar a sua própria criatividade. Ele nos lembra que, quando o analista não tem essa capacidade de brincar, precisa procurar outra tarefa para desempenhar (WINNICOTT, 1975). Afinal, o brincar deve, enquanto verbo e não substantivo, ser olhado como potencialidade humana intimamente ligada aos fenômenos transicionais.

\section{O que é um fenômeno transicional?}

Um fenômeno transicional refere-se a uma dimensão do viver que não se reduz nem à realidade interna nem à realidade externa. Este fenômeno acontece num lugar em que ambas as realidades (interna e externa) encontram-se, constituindo-se na experiência do brincar e, mais adiante, na experiência cultural. Especificamente em termos de amadurecimento emocional, esse conceito refere-se ao momento no qual se inicia a divisão eu/não-eu, o que pode ser um som, uma música ou uma melodia, por exemplo.

O objeto transicional, por sua vez, refere-se à primeira possessão não-eu, sendo assim caracterizado quando um objeto - seja cobertor ou ursinho de pelúcia - é usado transicionalmente. $\mathrm{O}$ objeto que tem, por exemplo, o cheiro da mãe, tem um valor para o bebê - não apenas pelo cheiro, mas também pela possibilidade de ter consigo a sensação de que a mãe existe e está com ele, consolidando o sentimento de continuidade da existência (SEKKEL, 2016).

Para desenvolver essa noção de objeto transicional, Winnicott (1941) partiu da observação de bebês em uma situação estabelecida, na clínica no Paddington Green Children's Hospital, em Londres. Foi observando o comportamento da criança com a espátula que ele começou a construir o conceito do brincar como fenômeno transicional que permite infinitas possibilidades rumo às experiências criativas

No primeiro momento desse jogo, o bebê, sentado no colo da mãe, observa uma espátula de metal; demonstrando interesse pelo objeto, hesita e tenta tocá-lo, mas, observando os adultos, freia seu desejo de obtê-lo, representando certa confiança no ambiente e em si mesmo. É preciso que os adultos aguardem e deixem que a brincadeira continue sendo espontânea. $\mathrm{O}$ segundo momento refere-se à manipulação da espátula, aceitando a realidade do desejo, colocando-a na boca, salivando e mastigando-a, "como se" estivesse comendo ou fumando. Quando o bebê está de posse do objeto, pode brincar de comidinha, junto com as pessoas ao seu redor: "Nunca vi qualquer evidencia de um bebê ficar desapontado com o fato de a espátula não ter, na verdade, nem comida, nem algo que contém comida", declarou Winnicott (1941, p.
142), caracterizando as primeiras experiências de representação e a capacidade de brincar. O terceiro momento é marcado pelo jogo da repetição do movimento de jogar o objeto e obtê-lo de volta. O bebê deixa a espátula cair por engano e um adulto a resgata; a partir disso, cria-se um jogo, deixando-a cair propositalmente. A criança brinca de jogar a espátula ao chão por várias vezes, até que deseja ir para o chão e brincar com o objeto até perder gradativamente o interesse e voltar-se para outro objeto.

Winnicott (1941) relaciona esse terceiro instante com o jogo fort-da, já descrito neste trabalho. O carretel, que representa a mãe, é jogado para longe, indicando um ato de livrar-se dela, podendo dominar a relação com a mãe interna, até mesmo pela agressividade ao desfazer-se dela e, depois, recuperá-la. A criança vai se tranquilizando em relação ao destino de sua mãe interna, sendo ativa no jogo e, assim, dando contorno aos seus ímpetos, sentindo confiança no ambiente, naquela mãe que vai e volta, que some e aparece. $\mathrm{O}$ brincar também possibilita que a criança domine a situação de separação da mãe e outras situações que possam causar sofrimento.

Deste ponto de partida que diz respeito ao processo de amadurecimento emocional da criança, podemos pensar sobre o que se passa na clínica psicanalítica. O jogo de espátula, recém-mencionado, relaciona-se ao jogo de rabisco proposto por Winnicott (1941), no âmbito da prática psicanalítica. Sua essência é a criação de um espaço transicional. O período inicial de hesitação no jogo de espátula pode ser transformado em um desabrochar criativo, como no rabisco e no desenhar. Partindo de algo sem forma, como um simples rabisco, é possível criar um sentido para a experiência. Paciente e terapeuta brincam juntos, modificando alternadamente o desenho um do outro, sendo um processo de construção conjunta. A partir desse espaço potencial, a criança passa a existir ou continua existindo, para depois aprender a criar, a sonhar e a brincar, vivenciando diferentes experiências culturais (WINNICOTT, 1941).

\section{O jogo do rabisco: uma vinheta clínica}

Em relação ao jogo do rabisco, nos remetemos a uma vinheta clínica de um caso atendido por uma das autoras deste trabalho. Joana ${ }^{1}$ tem sete anos e ficou em atendimento por pouco mais de um ano. É uma menina com a rotina agitada, encontrando dificuldades de tempo até para ir à terapia. Ela estuda em escola integral, é filha de pais separados que conversam entre si apenas sobre ela. A principal queixa era em relação à separação conturbada dos pais e à dificuldade de Joana de se "separar" da mãe, pois logo que os pais se separaram, quando ela tinha três anos, ela foi dormir na cama com a mãe e assim permaneceu. Hoje em dia, está caminhando para conseguir dormir sozinha. A guarda é da mãe, e o pai a encontra nos fins de semana, quinzenalmente, ou quando tem folgas no trabalho durante a semana.

Joana é uma menina que gosta muito de brincar, quase toda sessão chegava animada perguntando: "De que vamos brincar hoje?". Em alguns momentos, quase não

${ }^{1}$ Nome fictício. 
esperava um jogo acabar e logo perguntava qual seria o próximo, observando bem o que estava disponível na sala de atendimento. Ela demonstrava certa dificuldade em tolerar as perdas nos jogos e tentava até burlar algumas regras para vencer. Todavia, durante o processo de análise, pôde criar importantes recursos para lidar tanto com as perdas quanto com sua angústia de não querer sequer um intervalo entre uma brincadeira e outra. Também demonstrava certa resistência quando falávamos que o nosso tempo estava acabando. Com os nossos encontros contínuos e com a nossa disponibilidade para brincar, experienciamos, criativamente, possibilidades para que Joana pudesse aprender a criar, a sonhar e a brincar.

No início, quando as sessões acabavam, ela fazia uma voz diferente ao encontrar sua mãe na sala de espera, contando que gostaria de voltar a ser uma bebê bem pequena. Quando perdia nos jogos, ou Joana tentava trapacear e mudar as regras ou fazia esta voz, como se fosse uma tentativa de sedução para tentar alterar a realidade externa. Fomos brincando com esses aspectos para que ela pudesse notar que era preciso aprender com as perdas (tanto nos jogos como na vida: por exemplo, perder a convivência com os pais enquanto um casal) e que também era importante ir desenvolvendo seu sentimento de continuidade de existência. Brincando de querer voltar a ser bebê e brincando inúmeras vezes de casinha (onde a analista era a mãe e ela, a filha), ela conseguiu ser ela mesma e ir caminhando rumo à independência. Mesmo com alguns conflitos, Joana apresentava um bom potencial criativo e uma boa capacidade de brincar, e aos poucos ela foi aprendendo a perder e a se frustrar.

Com essa vinheta clínica, vemos que no brincar winnicottiano há uma topologia e uma temporalidade específicas. Em termos de espaço, ele não fica nem dentro e nem fora da subjetividade; fica na fronteira, no entre. Não está no espaço não-eu do bebê e nem inteiramente dentro de sua subjetividade e de seu corpo. Portanto, o brincar está no espaço potencial - que pode ser pensado como um espaço que vai se constituindo "entre" a mãe e o bebê - e posteriormente entre a criança e outras pessoas com quem se vincula, aplicando esta noção de espaço potencial para as sessões analíticas (FRANCO, 2003).

Em uma das sessões, ao propor o jogo do rabisco, foi interessante notar o movimento de Joana, que iniciou de forma colaborativa, buscando construir algo junto à ana- lista, mas depois tomou o desenho para si e o foi destruindo, fazendo novos rabiscos por cima. Ela dizia: "parece um tobogã...", mas depois escreveu: "montanha russa maluca. A montanha russa, ela explodiu e soltou um pum e fim". Este seu desenho pode ser visto na figura 1:

Figura 1: Jogo do rabisco
O sentido do conflito expresso no desenho parecia claro: o self de Joana, que até então estava sendo integrado, posteriormente foi sendo destruído, "explodindo e fim". Isso se deu a partir de uma situação externa, como a separação dos pais, que provocou alterações em sua rotina e em seu mundo interno. A partir daí, restou a Joana responder aos acontecimentos e não amadurecer de dentro para fora. Felizmente, a menina conseguia expressar isso, tanto por meio do desenho como por suas falas, num espaço que foi sendo construído no encontro entre analista e analisando. Mesmo com esse conflito, ela apresentava grandes recursos e uma capacidade de simbolização bem desenvolvida, caminhando bem no processo de análise.

Além dessa possibilidade de elaboração de conflitos e organização interna, o jogo do rabisco consiste em um espaço de experiência na sessão, um espaço potencial e uma experiência criativa, que proporciona a expansão do ser. É um momento em que terapeuta e paciente brincam juntos, divertem-se juntos, respeitando um ao outro, até mesmo no momento em que Joana precisou tomar o desenho para si e destruir - de certa forma - o que havia começado, para construir algo novo: de tobogã a montanha-russa.

O brincar, como uma sutileza entre o subjetivo e o objetivo, precisa ser entendido como algo além de uma visão romântica e agradável, considerando seu elemento, que pode se tornar assustador. Em alguns momentos, a criança precisa organizar a brincadeira antes de começar a brincar, tentando se prevenir desse aspecto assustador, ou então necessita que alguém fique observando e acompanhando, para que sua dimensão criativa seja preserva- 
da. Cabe ao analista sustentar essa capacidade de criar e de brincar (FRANCO, 2003). Na psicanálise, tanto com crianças como com adultos, o brincar é protagonista, precisando ser reconhecido em toda a sua potencialidade, valorizando também o setting como espaço intermediário para criação (FRANÇA; PASSOS, 2019).

Percebemos que esse brincar permite também a integração do self. O bebê, que se encontra em um estado inicial de não-integração, ao sentir confiança e segurança no ambiente, vai se desenvolvendo rumo à integração, assim como Joana caminhava. E esse caminho é facilitado pela experiência do brincar.

A transição do estado de não-integração para o estado de integração remete à evolução do funcionamento psíquico do princípio de prazer ao princípio de realidade, postulado por Freud (1911/1996c). Nesse texto, o autor afirma que, com a introdução do princípio de realidade, o fantasiar, que começa nas brincadeiras infantis e se conserva em forma de devaneio nos adultos, abandona a dependência de objetos reais, possibilitando a criação e a imaginação.

Em termos de constituição da criança, podemos nos remeter à proposta analítica de Winnicott (1975), destacando que o que é valorizado por ele no jogo do rabisco, todavia e diferentemente da proposta freudiana, não é o sentido do conflito em si ou o que os objetos simbolizam, mas sim a criação de um espaço de experiência, a partir do encontro com o outro. Nesse processo, pode ocorrer uma experiência de ser que parte de uma comunicação primária, que é subjetiva, para outra vivência de sentimento de integração, que está ligada aos objetos do mundo compartilhado. Essas comunicações ocorrem a partir do verdadeiro self, que é núcleo central da personalidade (LINS; LUZ, 1998).

A noção de transicionalidade refere-se ao viver criativo, à maneira pela qual cada um encontra de estar vivo e lidar com as realidades interna e externa, expandindo o verdadeiro self. Segundo Winnicott (1975, p. 100), a criatividade "está presente tanto no viver momento a momento de uma criança 'retardada' que frui o respirar, como na inspiração de um arquiteto ao descobrir subitamente o que deseja construir". Tudo isso se relaciona com a provisão ambiental, com a capacidade do ambiente se adaptar ao sujeito, de maneira suficientemente boa, e com a capacidade do sujeito de se adaptar ao ambiente, criando formas de lidar com sua realidade.

\section{$O$ ambiente suficientemente bom: outra vinheta clínica}

Quando o ambiente é suficientemente bom, é possível a continuidade dos processos de maturação da criança, podendo permitir que ela concretize o seu potencial. Esse ambiente suficientemente bom refere-se à apresentação contínua do mundo à criança, o que, necessariamente, aponta para falhas e para a imperfeição, pois é algo que não pode ser realizado mecanicamente, só podendo acontecer por meio do manejo de um ser humano (WINNICOTT, 1979/1983).
Ao mencionarmos esse cuidado tão caro a Winnicott, que diz respeito à importância da continuidade entre os diversos momentos por que passa a criança em seu amadurecimento, nos lembramos de uma experiência vivenciada por outra autora deste trabalho, com um bebê de noves meses. Este fato serve como um exemplo de acolhimento ao bebê por parte de um ambiente suficientemente bom, capaz de estar atento à importância de uma apresentação continuada do mundo à criança. Afinal, quando o bebê tem o sentimento de continuidade da existência, ele pode suportar o "desilusionamento" no qual, gradativamente, vai deixando a experiência de onipotência e aceitando a realidade compartilhada (MACIEL, 2016).

O bebê ao qual nos referimos frequentava uma creche, em tempo integral. Seus pais, de noite, quando iam colocá-lo para dormir, começaram a perceber que ele emitia um som (quase uma melodia musical). Preocupados, os pais foram procurar a diretora da referida instituição. Esta profissional chamou a cuidadora/educadora da criança, que esclareceu (ao pedir para os pais que reproduzissem o som que a criança emitia) que aquela era a música que cantava para os bebês quando iam dormir (na hora institucionalmente prevista para tal). Então o menino não estava em sofrimento (ao menos ainda!). De certa forma ele estava se ninando, estabelecendo uma continuidade entre os diversos momentos de dormir. Com esse esclarecimento, os pais decidiram também cantar a mesma música, em casa, ao colocarem o filho para dormir. Esse relato nos fez pensar na importância de um ritmo nos cuidados com o bebê, a fim de facilitar o seu sentimento de continuidade da existência. Afinal, podemos dizer, conforme Winnicott (1979/1983), que se sentir privado deste sentimento significa ser excluído do espaço do brincar.

Sabemos que, em termos cronológicos do amadurecimento emocional, o autor postulou que nos primeiros seis meses de vida há um estado de dependência absoluta da criança em relação ao meio; é um período em que, do ponto de vista do bebê, não há uma diferenciação entre "eu" e "outro". Mãe e bebê estão fundidos psiquicamente e há, também, uma dependência fisiológica absoluta. O segundo momento, de dependência relativa, acontece por volta dos seis meses aos dois anos (idade que tinha $o$ bebê do exemplo acima), em que a criança vai se descobrindo, aos poucos, como um ser diferente, separado da mãe e do mundo externo. Depois disso, as crianças vão adentrando no estágio de independência relativa, nunca alcançando a independência absoluta. Essa mudança da dependência absoluta rumo à independência é facilitada por meio dos objetos transicionais, que representam a passagem do bebê de uma fase inicial de indiferenciação com a mãe para o reconhecimento da mãe como algo externo e separado. O uso desses objetos vai se ampliando, tornando-se um espaço intermediário entre as realidades interna e externa, que se torna presente quando estamos criativos no mundo da cultura (WINNICOTT, 1975).

O uso do objeto, o manejo clínico e o brincar criativo 
Em relação ao uso do objeto, Winnicott (1975) traz uma novidade referente ao que acontece transferencialmente entre paciente e terapeuta. Dessa forma, amplia o conceito de transferência descrito inicialmente por Freud (1912/1996d). Para este último autor, a transferência está relacionada à repetição de protótipos infantis ligados às "imagos" parentais, podendo ser conscientes ou inconscientes, como são na maioria das vezes. Além disso, a transferência, na análise, surge como forma de resistência.

Winnicott, todavia, apresenta um novo olhar sobre esse fenômeno, ao defender que o que acontece transferencialmente na relação analítica inclui - além do que Freud (1912/1996d) postulou - as primeiras experiências do bebê ao se relacionar com sua mãe, de dependência absoluta, rumo à independência, fazendo uso de objetos de forma criativa. Parece-nos, nessa perspectiva, abrir-se para a transferência como aquilo que, enquanto experiência, pode criar algo novo que diz respeito ao uso do objeto.

Este uso não é instrumental, muito menos repetitivo, mas sim criativo. No processo analítico, o que permite a ampliação da capacidade do paciente em usar criativamente o objeto é o encontro com um analista espontâneo e autêntico, que possibilite fluir o verdadeiro self do seu paciente. Nesta relação, a confiança se mostra um elemento fundamental (MELLO FILHO, 2003).

Desse modo, a análise, tanto com crianças quanto com adultos, pode permitir a continuidade do sentimento de existência, o que se dá a partir da experiência de holding, que é propiciada pelo encontro com o outro, em um setting. $\mathrm{Na}$ abordagem winnicottiana, a análise seria uma metáfora dos cuidados maternos, em que o analista poderia funcionar como um espelho - como o olhar da mãe refletindo o rosto da criança -, sendo que cada analista poderia olhar e intervir, mostrando ao analisando quem ele é. $\mathrm{O}$ analista pode ser usado como um objeto transicional, adaptando-se às necessidades do analisando - de forma suficientemente boa-, permitindo o uso criativo do objeto ao brincar e criar junto (MELLO FILHO, 2003).

Hisada (2002) também enfatiza a importância que Winnicott dá ao setting na clínica psicanalítica, ao afirmar que essa noção se relaciona à ritmicidade, presente desde a relação mãe-bebê, como vimos no exemplo do bebê que frequentava a creche. Quando a mãe ou a cuidadora organiza o mundo de seu filho, compartilhando ritmos, oferece condições para o seu sentimento de continuidade de existência. No âmbito clínico, o ritmo nos processos criativos relaciona-se ao holding como metáfora dos cuidados maternos.

$\mathrm{O}$ manuseio do setting se torna fundamental, principalmente com pacientes mais regredidos, construindo um ambiente estável que proporcione a experiência de aconchego e de continuidade, sendo uma capacidade do analista em se dar ao paciente, estando disponível para brincar criativamente. O setting é, portanto, o que possibilita o manejo como procedimento clínico necessário, tanto na psicanálise com crianças quanto com adultos, quando houve falha no processo de amadurecimento (HISADA, 2002).
Na psicanálise com crianças torna-se importante o brincar criativo, em que cada um pode ir experimentando novas formas de estar no mundo. Por meio do encontro com o outro, é possível que sejamos criativos; imaginando situações, reproduzindo e criando momentos importantes da vida. No brincar, experienciamos tanto momentos de prazer quanto de desprazer, o que pode ser uma fonte de conhecimento sobre si e sobre o mundo. É um ato reflexivo e criativo, oferecendo condições de uma sensibilidade relacional, assumindo os paradoxos existentes. Nessa experiência, tanto crianças como adultos podem elaborar suas vivências e se manifestar criativamente perante as ações do mundo; além disso, torna-se possível ainda a criação e o fortalecimento do vínculo entre crianças e adultos, potencializando as suas tantas chances de constituição subjetiva (SOUSA; PEDROZA; VOLPE, 2019).

\section{Concluindo com a obra Anne with an " $e$ "}

Ao trazermos a reflexão do brincar como uma experiência criativa na psicanálise com crianças, recorremos primeiro às contribuições freudianas para depois adentrar nas particularidades winnicottianas, principalmente sobre o brincar como fenômeno transicional, relacionado ao sentimento de continuidade de existência e ao viver criativo. Esta compreensão tem a ver com o existir, que se inicia nas primeiras brincadeiras infantis e vai sendo transposto para todas as fases da vida humana. Para que haja uma continuidade de espaço, tempo e de sentimento de existência, é fundamental que se tenha um ambiente suficientemente bom, que inspire confiança. Essas ideias são também importantes no manejo clínico e na relação entre analista e analisando, por meio de um encontro entre as áreas lúdicas tanto do terapeuta quanto do paciente.

Com essas ideias, optamos por fazer uma conclusão do trabalho relacionada com um elemento da arte: Anne with an " $E$ " (ANNE..., 2017). É uma série de televisão canadense estreada em 2017, baseada no livro Anne de Green Gables, de 1908. Trata-se de uma adolescente que perdeu os pais ainda quando era bebê e viveu ora em orfanatos, ora na casa de outras famílias, cuidando de outras crianças, na década de 1890. Após uma vida de violências tanto nos orfanatos quanto na casa desses estranhos, ela é adotada pelos irmãos Marilla e Matthew Cuthbert.

É a história do amadurecimento da adolescente, que luta por aceitação e para encontrar o seu lugar no mundo. A trama oferece inúmeras reflexões, como da igualdade de gênero; no entanto, focaremos na relação de Anne com sua família adotiva. A personagem, mesmo com toda a dificuldade encontrada no mundo externo (de abusos nos orfanatos e nas famílias anteriores), apresentava uma importante capacidade interna de brincar, principalmente com as palavras, ao ler, falar ou escrever, fazendo uso desses recursos. Tanto a leitura como a escrita são usadas como fenômenos transicionais. Ela tinha habilidade para imaginar e criar uma realidade mais agradável do que a que existia, brincando com as palavras, mergulhando no mundo da leitura, encenando personagens e sonhando. 
A nossa escolha em trazer essa produção artística para o nosso trabalho foi por ressaltar uma personagem - Anne - que vivia criativamente e brincava em todos os âmbitos de sua vida. Isso nos fez lembrar os relatos de Clare Winnicott (1978) sobre a capacidade brincante de seu marido. $\mathrm{O}$ brincar, portanto, faz referência à qualidade do viver, $\mathrm{o}$ que vai além de brincar de jogos e brinquedos. Vai além da idade cronológica, sendo uma capacidade de operar na área intermediária sem limites. Mundo interno e externo vão se compondo na experiência do viver criativo. Clare e Donald Winnicott brincavam com as coisas, dando uma nova disposição a elas, de acordo com o humor.

Recuperando as ideias freudianas de que as brincadeiras infantis se relacionam com a fantasia, com a escrita criativa e com o devaneio, vemos como Anne se apropria de todos esses elementos ao viver sua adolescência. É uma personagem que sonha, que cria e que brinca. Pela leitura winnicottiana, podemos notar que Anne, mesmo com as adversidades, consegue ter uma linha de existência, expandindo o seu verdadeiro self. Por meio do brincar, ela vive criativamente, de forma espontânea e não submissa. Com seu jeito autêntico de ver e de criar o mundo, ela conquista as pessoas e - simultaneamente - encontra finalmente um ambiente seguro em Green Gables, por meio do cuidado e do amor de Marilla e de Matthew, que ocupam os lugares das figuras parentais.

Ainda que na série não haja nenhuma relação entre analista e analisando, conseguimos transpor nosso pensamento para o campo da análise, sobretudo com crianças. A construção de um setting facilitador é de extrema importância, bem como a presença de um analista suficientemente bom. A proposta analítica, tanto com crianças como com adultos, é a criação de uma sessão viva e alegre, possibilitada pela capacidade de brincar do analista e do analisando. $\mathrm{O}$ terapeuta, quando se adapta às necessidades do paciente, permite o uso criativo do objeto ao brincar e criar junto. Portanto, tanto a adoção de Anne quanto o encontro entre pacientes e terapeutas podem - de certa forma - reorganizar as vivências de mundo interno e externo. Marilla e Matthew estavam disponíveis para brincar e para aprender com Anne. Pensemos que, se Anne não tivesse encontrado um ambiente favorável à sua constituição, sua capacidade brincante e criativa poderia não emergir. Assim também pode acontecer em momentos de análise, pois possivelmente, se algumas crianças não encontrarem amparo em sua vida - o que pode ser representado pela figura do analista - poderão não continuar a sua linha de existência e, talvez, emergir um sujeito falso self.

Assim, o brincar - enquanto verbo e não substantivo - é olhado como potencialidade humana intimamente ligada aos fenômenos transicionais. É a este brincar enquanto verbo que nos referimos quando trazemos a experiência de Anne, que brinca até mesmo com os elementos da floresta quando caminha de sua casa para a escola. No momento em que o professor pede para que ela leia um texto, ela interpreta e dá vida a ele, com muita intensidade. Quando encontra outra professora, mais criativa e brincante, Anne se identifica e deseja ser como ela, inclusive em seus ide- ais feministas e de inovação em educação. Ela brinca com seus amigos da escola e também da fazenda de uma maneira muito criativa, sendo fiel a cada história que cria.

O brincar é muito mais do que um recurso técnico! É uma experiência criativa relacionada a todas as áreas do viver. Vemos como Anne faz uso de diferentes objetos: um simples galho ganha vida e pode se transformar em uma poderosa espada; uma coroa de flores, criada por ela mesma, a torna uma importante rainha; ou, ainda, sua lousa de giz vira um escudo para defendê-la. Na análise, importa perceber como analista e analisando estão usando os objetos, já que eles podem ser oferecidos, trocados ou recusados.

Por fim, notamos como Anne, Matthew e Marilla, enquanto família, foram se transformando durante a convivência. Podemos dizer que eles conseguiram viver criativamente e inspirar confiança, a partir de um encontro genuíno. No campo analítico, espera-se que as pessoas estejam disponíveis para brincar. Ao analista cabe a criação de um setting favorável e confiável, possibilitando que o potencial criativo se transforme em experiência criativa. Sigamos brincando e criando!

\section{Informações sobre as autoras:}

\section{Taisa Resende Sousa \\ (iD) https://orcid.org/0000-0002-0635-7209 \\ (9) http://lattes.cnpq.br/8296396405068174}

Doutora em Psicologia do Desenvolvimento e Escolar, pela Universidade de Brasília (UnB). Mestra em Psicologia em Processos de Desenvolvimento Humano e Saúde, pela mesma instituição. Membro do Laboratório LABPEP - Ágora Psychê. Psicóloga e Bacharel em Psicologia pela Universidade Federal de Uberlândia (UFU). Professora Substituta da Faculdade de Educação - Departamento Teoria e Fundamentos - UnB (de 2015 a 2016), nas seguintes disciplinas: Perspectiva do Desenvolvimento Humano, $\mathrm{O}$ educando com necessidades educacionais especiais e Introdução à classe hospitalar. Realização do curso de formação dos 7 Módulos Fundamentais sobre a obra de Sigmund Freud, no Centro de Estudos e Eventos Psicanalíticos de Uberlândia - CEEPU (252 horas) e realização do curso sobre os Fundamentos da Psicanálise de Winnicott (38 horas), organizado pelo grupo A psicanálise de Winnicott em Brasília. Interesse de estudos em: Psicanálise, Psicologia Clínica, Psicologia da Educação, Infância e Propostas de escolas transformadoras. Mãe de dois filhos: licença maternidade no segundo semestre de 2017 e no primeiro semestre de 2020.

\section{Regina Lúcia Sucupira Pedroza \\ (D) https://orcid.org/0000-0003-2251-5040 \\ (9) http://lattes.cnpq.br/7232661674377520}

Possui Graduação em Psicologia pela Universidade de Brasília (1988), graduação em Licenciatura em Psicologia pela Universidade de Brasília (1989), Mestrado em Psicologia pela Universidade de Brasília (1993), Doutorado em Psicologia pela Universidade de Brasília (2003) e Pós Doutorado em Sciences de l'Education pela Universidade Paris V, René Descartes (outubro 2009 a março de 2010). Atualmente é Profa. Associada da Universidade de Brasília no Instituto de Psicologia. Tem experiência na área de Psicologia, com ênfase em Desenvolvimento e Psicologia Escolar, atuando principalmente nos seguintes temas: educação, formação de professor, formação de educadores para educação em direitos humanos, formação da personalidade, o brincar no desenvolvimento humano, psicanálise e psicologia do Esporte. Orientadora de mestrado e doutorado no Programa de Pós-Graduação em Processos de Desenvolvimento Humano e Saúde. Orientadora de mestrado no Programa de Pós-Graduação em Direitos Humanos 
e Cidadania. Conselheira do CFP, gestão 2017-2019. Coordena na UnB o PROCAD/Amazônia CAPES/FAPEAM, UFAM, UnB, UNIR. É pesquisadora no CAPES PRINT/UnB, nos planos de trabalho do Ágora Psyché (PGPDS) e do PSICC.

Maria Regina Maciel

(iD) https://orcid.org/0000-0001-9579-0209

(3) http://lattes.cnpq.br/1138399747473192

Possui graduação em Psicologia pela Universidade Santa Úrsula (1989), mestrado em Psicologia pela Pontifícia Universidade Católica do Rio de Janeiro (1994) e doutorado em Saúde Coletiva pela Universidade do Estado do Rio de Janeiro (2003). Atualmente é professora associada da Universidade do Estado do Rio de Janeiro (UERJ) e membro efetivo do Círculo Psicanalítico do Rio de Janeiro. Tem experiência na área de Psicologia, com ênfase em psicanálise e educação. Dedica-se principalmente aos temas: infância, psicanálise, educação e contemporaneidade.

\section{Contribuições das autoras:}

Todas as autoras colaboraram ao longo do processo, desde a elaboração até a revisão final do manuscrito. As autoras aprovaram o manuscrito final para a publicação.

\section{Como citar este artigo:}

\section{ABNT}

SOUSA, Taisa Resende; PEDROZA, Regina Lúcia Sucupira; MACIEL, Maria Regina. O brincar como experiência criativa na psicanálise com crianças. Fractal: Revista de Psicologia, Niterói, v. 32, n. 3., p. 269-276, set./out. 2020. https://doi.org/10.22409/19840292/v32i3/5754

\section{APA}

Sousa, T. R., Pedroza, R. L. S., \& Maciel, M. R. (2020, Setembro/ Outubro). O brincar como experiência criativa na psicanálise com crianças. Fractal: Revista de Psicologia, 32(3.), 269-276. doi: https://doi.org/10.22409/1984-0292/v32i3/5754

\section{Copyright:}

Copyright (C) 2020 Sousa, T. R., Pedroza, R. L. S., \& Maciel, M. R. Este é um artigo em acesso aberto distribuído nos termos da Licença Creative Commons Atribuição que permite o uso irrestrito, a distribuição e reprodução em qualquer meio desde que o artigo original seja devidamente citado.

Copyright (C) 2020 Sousa, T. R., Pedroza, R. L. S., \& Maciel, M. $\mathrm{R}$. This is an Open Access article distributed under the terms of the Creative Commons Attribution License, which permits unrestricted use, distribution, and reproduction in any medium, provided the original article is properly cited.

\section{Referências}

ANNE with an "E" [seriado]. Direção: Moira Walley-Beckett. Produção: Miranda de Pencier e Susan Murdoch. Ontário, Canadá: 2017-2019. CBC/Netflix. 4k (Ultra HD) Dolbi digital 5.1.

FRANÇA, Rafaela Mota Paixão; PASSOS, Maria Consuêlo. Ensaio sobre o método clínico na psicanálise com crianças. Revista Latinoamericana de Psicopatologia Fundamental, São Paulo, v. 22, n. 4, p. 749-767, dez. 2019. http://dx.doi. org/10.1590/1415-4714.2019v22n4p749.6

FRANCO, Sérgio de Gouvêa. O brincar e a experiência analítica. Ágora, Rio de Janeiro, v. 6, n. 1, p. 45-59, jun. 2003. https://doi.org/10.1590/S1516-14982003000100003

FREUD, Sigmund. Escritores criativos e devaneios (1907) In: SALOMÃO, J. (Org.). Obras Psicológicas Completas de Sigmund Freud. Rio de Janeiro: Imago, 1996a. Edição Standard Brasileira, v. 9, p. 132-143.
FREUD, Sigmund. Análise de uma fobia em um menino de cinco anos (1909). In: SALOMÃO, J. (Org.). Obras Psicológicas Completas de Sigmund Freud. Rio de Janeiro: Imago, 1996b. Edição Standard Brasileira, v. 10, p. 12-133.

FREUD, Sigmund. Formulações sobre os dois princípios do funcionamento mental (1911). In: SALOMÃO, J. (Org.). Obras Psicológicas Completas de Sigmund Freud. Rio de Janeiro: Imago, 1996c. Edição Standard Brasileira, v. 12, p. 233-244.

FREUD, Sigmund. A dinâmica da transferência (1912). In: SALOMÃO, J. (Org.). Obras Psicológicas Completas de Sigmund Freud. Rio de Janeiro: Imago, 1996d. Edição Standard Brasileira, v. 12, p. 109-119.

FREUD, Sigmund. Da história de uma neurose infantil: o homem dos lobos (1918). In: SALOMÃO, J. (Org.). Obras Psicológicas Completas de Sigmund Freud. Rio de Janeiro: Imago, 1996e. Edição Standard Brasileira, v. 17, p. 15-129.

FREUD, Sigmund. Além do princípio do prazer (1920). In: SALOMÃO, J. (Org.). Obras Psicológicas Completas de Sigmund Freud. Rio de Janeiro: Imago, 1996f. Edição Standard Brasileira, v. 18, p. 2-75.

HISADA, Sueli. Clínica do setting em Winnicott. Rio de Janeiro: Revinter, 2002.

LINS, Maria Ivone Accioly; LUZ, Rogerio. D. W. Winnicott: experiência clínica e experiência estética. Rio de Janeiro: Revinter, 1998.

MACIEL, Maria Regina. Psicanálise e educação. São Paulo: Casa do Psicólogo, 2016.

MELLO FILHO, Julio. O ser e o viver: uma visão da obra de Winnicott. São Paulo: Casa do Psicólogo, 2003.

SEKKEL, Marie Claire. O brincar e a invenção do mundo em Walter Benjamin e Donald Winnicott. Psicologia USP, São Paulo, v. 27, n. 1, p. 86-95, abr. 2016. https://doi. org/10.1590/0103-656420140016

SOUSA, Taísa Resende. Psicanálise, educação e infância: experiência de educação criativa e brincante em uma comunidade de aprendizagem. 2019. 181 f. Tese (Doutorado)Programa de Pós-graduação em Psicologia da Universidade de Brasília, Brasília, 2019.

SOUSA, Taísa Resende; PEDROZA, Regina Lúcia Sucupira; VOLPE, Maira Muhringer. Concepções de crianças da educação infantil sobre violência e a relação com o brincar: contribuições de Freud e Winnicott. Revista Interação em Psicologia, v. 23, n. 1, p. 75-84, 2019. http://dx.doi.org/10.5380/psi.v23i1.56020

WINNICOTT, Donald W. Observação de bebês em uma situação estabelecida. In: . Textos selecionados - da Pediatria à Psicanálise. Tradução de Jane Russo. Rio de Janeiro: Francisco Alves, 1941. p. 139-164.

WINNICOTT, Donald W. O brincar e a realidade. Rio de Janeiro: Imago, 1975.

WINNICOTT, Donald W. A reflection. In: GROLNICK, Simon A.; BARKIN, Leonard; MUENSTERBERGER, Werner (Ed.) Between fantasy and reality: transitional objects and phenomena. New York: Routledge, 1978. p. 15-33.

WINNICOTT, Donald W. O ambiente e os processos de maturação: estudos sobre a teoria do desenvolvimento emocional (1979). Porto Alegre: Artes Médicas, 1983. 